\title{
Health Disparities and Access to Healthcare in Rural vs. Urban Areas
}

\author{
Megan Reilly ${ }^{1}$
}

Individuals and families in rural areas face disparities in health as well as access to healthcare. Research has found that when compared to urban communities, rural areas have worse health outcomes including challenges with mental health, substance abuse, physical health, and sexual health. Relevant findings have also shown that in order to understand these challenges it is important to discuss access, including the different factors involved: availability, affordability, and acceptability. Along with defining access, there are several theories and frameworks that additionally help explain healthcare access in rural areas. Although availability, affordability, and acceptability are important variables when it comes to access, there are also several barriers that must be considered, including poverty, occupation, education, insurance, and lack of competence. Once all of these aspects are addressed, different strategies can be more easily implemented in order to improve health and access to care in rural areas. These different disparities in heath and access to care can be seen throughout the North Country, and can be helpful in understanding the larger pattern of health in rural and urban areas. [Article copies available for a fee from The Transformative Studies Institute. E-mail address: journal@transformativestudies.org Website: http://www.transformativestudies.org (C2021 by The Transformative Studies Institute. All rights reserved.]

KEYWORDS: Rural Health, Rural Healthcare Disparities, Rural vs. Urban, North Country.

\footnotetext{
${ }^{1}$ Megan Reilly, is originally from Ithaca, New York and graduated from St. Lawrence University in May of 2019 with a BS in Psychology. She currently works at Brigham and Women's Hospital as a Clinical Research Coordinator for the national research program All of Us. Megan is passionate about equity in healthcare and looking forward to continuing her career as she applies to Physician Assistant school. Address correspondence to: Megan Reilly, e-mail: mreilly13@bwh.harvard.edu.
} 